\title{
Online-Learning due to COVID-19 Improved Mental Health Among Medical Students
}

\author{
Aidos K. Bolatov ${ }^{1}$ (D) - Telman Z. Seisembekov ${ }^{1}$ (D) - Altynay Zh. Askarova ${ }^{1}$ (D) - Raushan K. Baikanova ${ }^{1}$ (D) \\ Dariga S. Smailova ${ }^{2}$ (1) $\cdot$ Elisa Fabbro ${ }^{3}$ (1)
}

Accepted: 8 November 2020 / Published online: 18 November 2020

(C) International Association of Medical Science Educators 2020

\begin{abstract}
In reference to the announcement of the pandemic of the new coronavirus 2019-(nCoV), all educational institutions in the Republic of Kazakhstan have switched to online learning (OL). The purpose of this study was to investigate the mental state of the medical students switching to OL in comparison with the mental state of the students who had traditional learning (TL). A repeated questionnaire-based cross-sectional study was conducted among medical students ranging from 1st year to 5th year at Astana Medical University in the 2019-2020 academic year. The first study was conducted during the TL (October-November $2019, N=619$ ), and the second study was conducted during the OL period (April 2020,N=798). Burnout syndrome, depression, anxiety, somatic symptoms, and satisfaction with academic performance have been studied. The findings revealed that prevalence of the burnout syndrome, depression, anxiety, and somatic symptoms decreased after transitioning from TL to OL. However, during the OL period, the prevalence of colleague-related burnout increased, which tells us about the negative impact of OL on students' communication and interpersonal relationships. The most common depression and anxiety symptoms, dissatisfaction with academic performance were among students who indicated a decrease in academic performance during OL. Students who lived alone during the quarantine were more prone to depression during OL. In conclusion, during the quarantine period after the transition from TL to OL, the mental health state of medical students improved, despite the severe conditions of the pandemic.
\end{abstract}

Keywords Online learning $\cdot$ COVID-19 $\cdot$ Medical students $\cdot$ Mental health

Aidos K. Bolatov

bolatovaidos@gmail.com

Telman Z. Seisembekov seisembekov@mail.ru

Altynay Zh. Askarova altonchiks@gmail.com

Raushan K. Baikanova

baikanova.r@amu.kz

Dariga S. Smailova

dari190490@gmail.com

Elisa Fabbro

elisa.fabbro@uniud.it

1 Astana Medical University, Beybitshilik St. 49A, Nur-Sultan, Kazakhstan Z10K9D9

2 Semey Medical University, Abay Kunanbayev St. 103, Semey, Kazakhstan F17G0D3

3 University of Udine, Via Colugna 50, 33100 Udine, Italy

\section{Introduction}

One of the global services significantly affected by the coronavirus disease (COVID-19) pandemic is the medical education sector [1]. While the spread of the virus has had farreaching consequences, the closure of universities has led to the emergence of innovative methods of providing education that ensure the continued education of students [2]. The implications of these changes on the development of medical students and their mental health remain to be determined [3]. According to one systematic review of the impact of the COVID-19 pandemic on the mental well-being of people, it can be concluded that many segments of the population have experienced a negative impact on their mental state. A study conducted among the Iranian population showed that medical students had significantly higher scores for stress, anxiety, and depression compared with that of medical staff and community populations [4]. Fear of a new virus, social distancing, job loss, and increased media attention, along with a lack of 
information and knowledge about the pandemic, has created and exacerbated feelings of insecurity, depression, and anxiety [5]. Moderate to high level of anxiety in COVID-19 has a significant association with general somatic symptoms, in particular, fatigue symptoms and gastrointestinal symptoms [6]. Moreover, the chronic stress caused by the pandemic has led to many physical symptoms, such as headaches, insomnia, digestive problems, hormonal imbalances, and fatigue [7].

By order (No. 30 dated 03/13/2020) of the Rector of Astana Medical University (AMU), from March 16, 2020, training was transferred to online learning $(\mathrm{OL})$. OL is the use of electronic technology and media to deliver support and enhance both learning and teaching which involves communication between learners and teachers utilizing online content [8]. In AMU, the process of OL was organized by using Modular Object-Oriented Dynamic Learning Environment (Moodle), an online learning management system and different platforms like Zoom, Skype, and WebEx for video conferencing. The use of written and oral methods was different depending on the subject and profile of the training.

Rajab et al. in a cross-sectional study among Saudi Arabian medical students specifying challenges in online learning indicated pandemic-related anxiety and stress [9]. Duraku and Hoxha indicated a lack of attention and focus and decreased motivation to attend lessons and study during the COVID-19 pandemic [10]. The jump into online systems was associated with a decrease in motivation, self-efficacy, and cognitive engagement [11]. In a study conducted among more than 30,000 students from 62 countries in isolation and the transition to OL, the authors concluded that students were mostly worried about the problems associated with their future professional careers and studies, and also experienced boredom, anxiety, and frustration [12].

The transition from the medical school setting to home results in isolation [1]. Schaeffer and Konetes found that OL students are more likely to discontinue their studies than students following traditional education (TL). Moreover, social isolation during OL was the main factor affecting students' ability to study [13]. Kahl and Cropley stated that students learning remotely were more "isolated" than TL students, and had a lower level of self-confidence [14]. Social isolation may cause anxiety and depression [15]. Lazarevic and Bentz indicated a significant lower level of perception of stress associated with learning in an online group compared to students who took a course in a class [16]. Whereas in Hendrix's study, the level of perceived stress between students studying online and students studying TL was not significantly different [17]. Haider and Al-Salman analyzing dataset of 775 Jordanian university students found after COVID-19 sleep compliance dropped by more than 50\%; more than $80 \%$ of respondents indicated that prolonged use of digital tools for learning affected their sleeping habits; more than $90 \%$ of students indicated that continuous exposure to electronic screens in OL is tiring and exhausting; $89 \%$ of respondents agreed that prolonged use of e-learning tools often led to boredom, nervousness, and tension; and $73 \%$ of students do not recommend continuing with the online learning model because it is socially and psychologically unhealthy [18].

Gossenheimer et al. showed that cognitive factors, such as academic experience, academic performance, and distance learning formats, are comparable to those observed in the traditional form of training [19]. Pei and Wuin's systematic review concluded that OL has advantages to enhance knowledge and skills of medical student compared to the TL format [20]. However, Hasan and Bao concluded that "e-Learning crack-up" perception had a significant positive impact on student's psychological distress, and the fear of academic year loss was the crucial factor responsible for psychological distress during COVID-19 lockdown [21].

Moreover, the study of medicine, in which the development of practical skills is a significant proportion of the course, has not previously been envisaged through OL. However, the COVID-19 pandemic forced the medical education system to temporarily switch to OL.

Before quarantine with COVID-19, students of Astana Medical University (AMU) studied in the TL system, and the forced measure to transition to OL became a new challenge for students. In the context of the above data, we aimed to compare the indicators of the mental state of medical students (burnout syndrome, depression, and anxiety) during TL and OL.

\section{Materials and Methods}

\section{Study Design}

This study used a questionnaire with a cross-sectional survey design. A questionnaire where students independently and anonymously reported their experience was used as a method of data collection. The variables were sex, year of study, training format, and levels of burnout, depression, anxiety, and satisfaction with academic performance.

\section{Participants and Procedure}

The study was attended by 1 st to 5 th year students, who are enrolled in the "General Medicine" course at AMU. Participants were invited via the "messengers" app and the university's information portal, Sirius, to fill out an online questionnaire created on the $1 \mathrm{ka}$ platform (www.1ka.si). The questionnaire is attached as Electronic Supplementary Material 1 (ESM1). The first part of the study was conducted during the TL period (October-November 2019). 
The second study was completed during the OL period (April 13-19, 2020).

The total number of respondents in the TL sample was 619 , with an average age of 19.14 (in the range of 17-27). In the OL sample, $N=798$, with an average age of 20.31 (17-33). The gender distribution in the two studies was equal. In the TL study, $25.0 \%$ of participants were male, while in the OL study, $24.3 \%$ were male. Academic year distribution among TL students was 1 year (223), 2 year (139), 3 year (130), 4 year (64), and 5 year (63); among OL students: 1 year (139), 2 (118), 3 (269), 4 (226), and 5 year of study (46).

\section{Materials}

The questionnaire included:

- Socio-demographic and personal characteristics (gender, age, year of study, etc.).

- The Copenhagen Burnout Inventory (CBI-S) developed by Kristensen et al. [22], and adapted for students by Campos, Carlotto, and Maroco, was used to assess burnout syndrome [23]. This scale consists of 25 items that represent 4 subscales: Personal Burnout (PB), Studiesrelated Burnout (SRB), Colleague-related Burnout (CRB), and Teacher-related Burnout (TRB). The answered options ranged from "always," "frequently," "sometimes," "rarely," to "never." This was quantified as $100,75,50,25$, and $0 \%$ respectively, with a reverse scoring for item 10. For each scale, a total average score was calculated. According to Kristenson's criteria of burnout, scores for a respective level of 50 to 74 were considered moderate, 75-99 were high, and a score of 100 was considered as severe burnout [24]. CBI-S has demonstrated excellent internal consistency (Cronbach's $a=0.943$ ).

- The Patient Health Questionnaire-9 (PHQ-9) scale was used to assess depression [25]. This scale consisted of 9 questions. The participant had to respond to the question: "How often have they been bothered by the following (by what) over the past 2 weeks?". Each question had four possible answers and ratings: "Not at all" (0), "Several days" (1), "More than half of the days" (2), "Nearly every day" (3). The total score was calculated and interpreted as follows: 0-4 scores (Minimal or none), 5-9 scores (Mild), 10-14 scores (Moderate), 15-19 scores (Moderately severe), and 20-27 (Severe). Participants with scores higher than 10 were considered depressed [26]. PHQ-9 has demonstrated good internal consistency (Cronbach's $a=$ 0.890).

- The Generalized Anxiety Disorder, the 7-item (GAD-7) scale was used to assess anxiety [27]. This scale consists of 7 questions. Participants needed to answer to the question "How often have they been bothered by the following over the past 2 weeks?". Each question had four possible answers and ratings: "Not at all" (0), "Several days" (1), "More than half the day" (2), "Nearly every day" (3). The total score was calculated according to the results and interpreted as follows: 0-4 scores (Minimal), 5-9 scores (Mild), 10-14 scores (Moderate), and 15-21 scores (Severe). Participants with scores higher than 10 were considered to be anxious [26]. GAD-7 has demonstrated excellent internal consistency (Cronbach's $a=0.907$ ).

- The Patient Health Questionnaire-15 (PHQ-15) scale was used to assess common physical symptoms. It consists of 15 items, with a score of $0-2$ points for each item, and 30 points total. A cutoff score of 5,10 , and 15 points indicates low, medium, and high severity of somatic symptoms, respectively [28]. Students scoring higher than 10 were considered having medium to highly severe somatic symptoms. PHQ-15 has demonstrated good internal consistency (Cronbach's $a=0.882$ ).

- Fear of COVID-19 was assessed using a 5-point adapted Snell's questionnaire (Snell's questionnaire regarding fear of AIDS) [29]. Results $\geq 3$ were assessed as having fear of COVID-19. Snell's questionnaire has demonstrated excellent internal consistency (Cronbach's $a=0.901$ ).

The study was approved by the Local Ethics Committee of AMU (extract from protocol No. 3 of September 20, 2018).

\section{Data Analysis}

Statistical analysis was performed using Microsoft Excel and IBM SPSS Statistics 20.0. A statistically significant difference was accepted with a $p$ value less than 0.05 .

Descriptive statistics were performed with the calculation of the mean (M) and standard deviation (SD) for quantitative variables; percentages were calculated for qualitative variables. The chi-squared test or independent sample $t$ test was used to assess the differences between variables. To compare the results within one sample, ANOVA analysis with the Bonferroni post hoc test was used. To evaluate independent variable associations, a logistic regression analysis was performed.

\section{Results}

The level and prevalence of burnout syndrome depending on gender and the year of study in the period of TL and OL are presented in Table 1. The level and prevalence of burnout syndrome among students during TL was $27.6 \%$, while, during the period of OL, this indicator dropped to $16.7 \%$ (decreased by 1.6 times). The average scores for CBI-S subscales in two studies are shown in Table 2. Comparative analysis of the average values of each item of the CBI-S by $t$ test is attached as Electronic Supplementary Material 2 (ESM2). 
Table 1 The level and prevalence of burnout syndrome during the period of TL $(N=619)$ and OL $(N=798)$

\begin{tabular}{|c|c|c|c|c|c|}
\hline Variables & & $\begin{array}{l}\text { Burnout syndrome during TL } \\
\%, \mathrm{M}(\mathrm{SD})\end{array}$ & $\begin{array}{l}\text { Burnout syndrome during OL } \\
\%, \mathrm{M}(\mathrm{SD})\end{array}$ & $\begin{array}{l}t \text { test } \\
t \text {-score, } p\end{array}$ & $\chi^{2}, p$ \\
\hline \multirow[t]{2}{*}{ Gender } & Male & $30.3 \%, 38.88(19.18)$ & $12.9 \%, 31.11(19.02)$ & $3.78,<0.001$ & $65.15,<0.001$ \\
\hline & Female & $26.7 \%, 40.06(17.58)$ & $15.2 \%, 33.14(17.16)$ & $6.46,<0.001$ & $28.58,<0.001$ \\
\hline \multirow[t]{5}{*}{ Year of study } & 1 year & $18.4 \%, 34.73(18.25)$ & $13.8 \%, 33.13(17.96)$ & $0.82,0.415$ & $5.65,<0.05$ \\
\hline & 2 year & $43.9 \%, 45.74(16.65)$ & $18.6 \%, 32.02(18.44)$ & $6.27,<0.001$ & $107.80,<0.001$ \\
\hline & 3 year & $29.2 \%, 40.82(17.08)$ & $13.4 \%, 32.37(17.89)$ & $4.49,<0.001$ & $53.96,<0.001$ \\
\hline & 4 year & $21.9 \%, 40.19(15.58)$ & $14.3 \%, 32.58(17.25)$ & $3.18,<0.05$ & $14.17,<0.05$ \\
\hline & 5 year & $27.0 \%, 41.80(19.53)$ & $15.2 \%, 34.85(15.43)$ & $2.00,<0.05$ & $30.06,<0.001$ \\
\hline Total & & $27.6 \%, 39.77(17.98)$ & $16.7 \%, 32.65(17.64)$ & $7.47,<0.001$ & $24.84,<0.001$ \\
\hline
\end{tabular}

$T L$, tradition learning; $O L$, online-learning; $M$, mean; $S D$, standard deviation

Analysis of these results showed that there was no significant difference in the average CBI-S scores between male and female students during the TL period. A post hoc test indicated a significant difference between 1 st and 2 nd year students, 1 st and 3rd students, and 1 st and 5 th year students $(p<0.05)$.
Analysis of variance among students in the period of OL did not reveal a significant difference between gender and the year of study.

During TL, the prevalence of PB in students was $55.7 \%$, the prevalence of SRB was $54.9 \%$, and the prevalence of CRB

Table 2 The level of burnout syndrome measured by subscales of the CBI-S, among students ranging from 1 st year to 5 th year in the period of TL $(N=$ $619)$ and $\mathrm{OL}(N=798)$

\begin{tabular}{|c|c|c|c|c|}
\hline CBI-S subscales & Year of study & $\begin{array}{l}\text { Burnout syndrome during TL } \\
\mathrm{M} \text { (SD) }\end{array}$ & $\begin{array}{l}\text { Burnout syndrome during OL } \\
\text { M (SD) }\end{array}$ & $\begin{array}{l}T \text { test } \\
T \text {-score, } p\end{array}$ \\
\hline \multirow[t]{6}{*}{ PB } & 1 year & $43.72(20.39)$ & $38.46(21.16)$ & $2.35,<0.05$ \\
\hline & 2 year & $60.82(19.83)$ & $37.25(23.36)$ & $8.75,<0.001$ \\
\hline & 3 year & $55.86(21.11)$ & $37.30(20.74)$ & $8.33,<0.001$ \\
\hline & 4 year & $50.52(18.39)$ & 36.95 (20.64) & $4.75,<0.001$ \\
\hline & 5 year & $51.78(22.02)$ & 44.37 (18.68) & $1.85,0.067$ \\
\hline & Total & $51.64(21.42)$ & $37.80(21.10)$ & $12.20,<0.001$ \\
\hline \multirow[t]{6}{*}{ SRB } & 1 year & $42.49(34.10)$ & 42.35 (22.64) & $0.06,0.955$ \\
\hline & 2 year & $60.34(23.11)$ & $41.06(23.78)$ & $6.58,<0.001$ \\
\hline & 3 year & $54.90(22.86)$ & 39.91 (21.93) & $6.31,<0.001$ \\
\hline & 4 year & $51.56(19.90)$ & $38.95(20.07)$ & $4.45,<0.001$ \\
\hline & 5 year & $51.92(23.19)$ & $44.03(18.91)$ & $1.89,0.061$ \\
\hline & Total & $51.00(24.09)$ & 40.47 (21.67) & $8.64,<0.001$ \\
\hline \multirow[t]{6}{*}{ CRB } & 1 year & $24.12(21.55)$ & $25.66(23.98)$ & $0.63,0.528$ \\
\hline & 2 year & $24.76(22.59)$ & $24.54(19.30)$ & $0.08,0.935$ \\
\hline & 3 year & $21.06(20.70)$ & $25.65(23.17)$ & $1.92,0.056$ \\
\hline & 4 year & $26.63(19.01)$ & $27.25(24.03)$ & $0.19,0.848$ \\
\hline & 5 year & $27.38(22.76)$ & $25.00(21.07)$ & $0.55,0.580$ \\
\hline & Total & $24.21(21.51)$ & $25.90(22.88)$ & $1.42,0.157$ \\
\hline \multirow[t]{6}{*}{ TRB } & 1 year & $28.59(23.95)$ & $26.05(22.14)$ & $1.01,0.313$ \\
\hline & 2 year & $37.05(23.45)$ & $25.22(22.09)$ & $4.14,<0.001$ \\
\hline & 3 year & $31.44(22.88)$ & $26.61(22.24)$ & $2.01,<0.05$ \\
\hline & 4 year & $32.03(22.01)$ & 27.15 (21.38) & $1.60,0.109$ \\
\hline & 5 year & $36.11(26.91)$ & $26.00(21.92)$ & $2.09,<0.05$ \\
\hline & Total & $32.21(23.91)$ & $26.42(21.89)$ & $4.74,<0.001$ \\
\hline
\end{tabular}

$T L$, tradition learning; $O L$, online-learning; $M$, mean; $S D$, standard deviation; $C B I-S$, Copenhagen Burnout Inventory-Student Survey; $P B$, personal burnout; $S R B$, studies-related burnout; $C R B$, colleague-related burnout; $T R B$, teacher-related burnout 
was $13.1 \% .24 .1 \%$ of students suffered from TRB. During the OL, distribution of $\mathrm{PB}, \mathrm{SRB}, \mathrm{CRB}$, and TRB was $31.2 \%$, $34.1 \%, 17.0 \%$, and $17.9 \%$, respectively. Comparing these variables between students during TL and OL, there was a significant difference for PB and SRB $(p<0.001)$, and for CRB and TRB $(p<0.05)$.

Severity of depression among students during TL and OL is presented in Fig. 1a. During OL, depression occurs in $27.6 \%$ of students, while during TL depression manifested in $49.3 \%$ of students $\left(\chi^{2}=50.83, p<0.001\right)$.

Depending on the students' year of study in the course, the prevalence of depression during TL and OL was statistically different: in 2nd year $(p<0.001)$, in 3 rd year $(p=0.003)$, and in 4 th year $(p=0.023)$. Depression symptoms were significantly more prevalent in students during TL $(p<0.001)$ - this is regardless of gender or academic level of students.

Severity of anxiety among students of the two forms of training is illustrated in Fig. 1b. During TL, anxiety was noted in $42.3 \%$ of respondents, and during OL: $15.5 \%\left(\chi^{2}=93.07, p\right.$ $<0.001)$. Regardless of gender or the year of study, the prevalence of anxiety was significantly lower among students enrolled in the period of OL $(p<0.05)$. In the period of TL, anxiety was significantly more common among females $(p<$ 0.05 ), whereas, in the period of OL, the gender difference was not significant.

Medium to highly severe somatic symptoms were more common among students in the period of TL compared to the OL period $\left(63.6 \%\right.$ vs $\left.19.4 \%, \chi^{2}=218.60, p<0.001\right)$. Figure 2 compares the frequency of somatic symptoms between TL and OL students. Differences in all items according to learning format were significant $(p<0.001)$. During TL, women more often complain about back pain, headaches, dizziness, feeling tired $(p<0.001)$, stomach pain, constipation or diarrhea, trouble sleeping $(p<0.05)$. During OL, headaches $(p$ $<0.001$ ), back pain, feeling tired, and trouble sleeping ( $p<$ 0.05 ) were more common in women. The most common somatic symptoms during OL (period of COVID-19 pandemic) associated with depression and anxiety: insomnia, fatigue, headaches, back pain $(p<0.001)$, and menstrual pain $(p<$ 0.05).

Satisfaction with academic performance was assessed by the students' response to the question: "Are you satisfied with your academic performance?" During the period of TL, 375 students responded: $50.4 \%$ of them were satisfied with their academic performance; while in the period of OL 750 students responded and $71.6 \%$ were satisfied with their academic performance $\left(\chi^{2}=56.98, p<0.001\right)$. The response to the question "How has your academic performance changed since you switched to distance education?" was $30.6 \%$ of students answered that their academic performance had improved, for $17.7 \%$ of the respondents it weakened, and $51.7 \%$ indicated that their academic performance had remained the same. OL studying was difficult for $38.1 \%$ of the students, while $61.9 \%$ answered that it was not difficult for them. Fifty-four percent of students indicated that OL had more positive aspects than negative ones. However, satisfaction with academic performance is not associated with difficulties in OL.

Logistic regression analysis showed changes in academic performance with regard to burnout syndrome, depression, anxiety, and dissatisfaction with academic performance
Fig. 1 Severity of depression (a) and anxiety (b) among medical students during TL $(N=619)$ and OL $(N=798)$

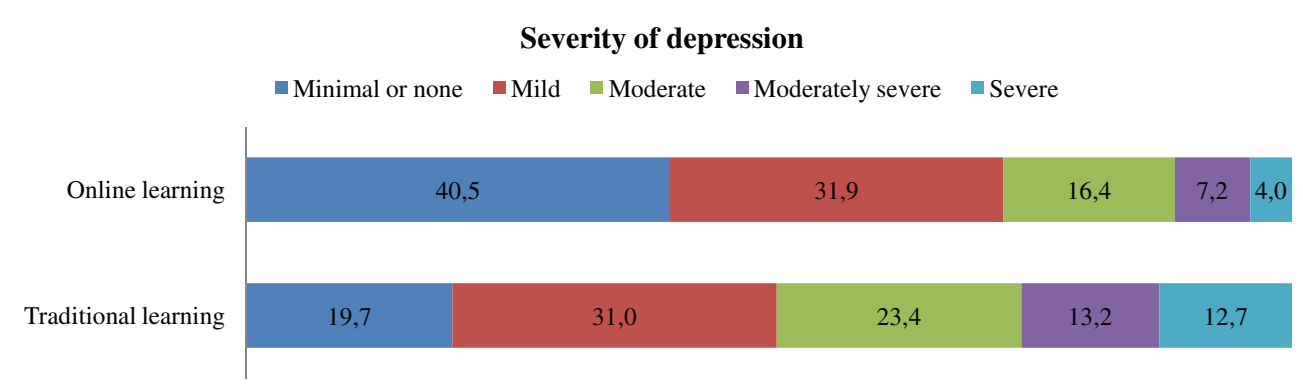

(a)

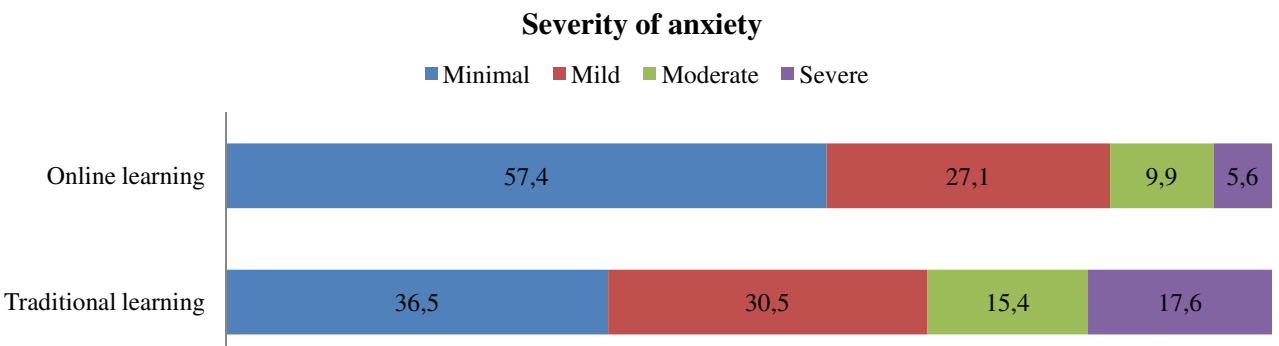

(b) 
Traditional learning period

Online learning period

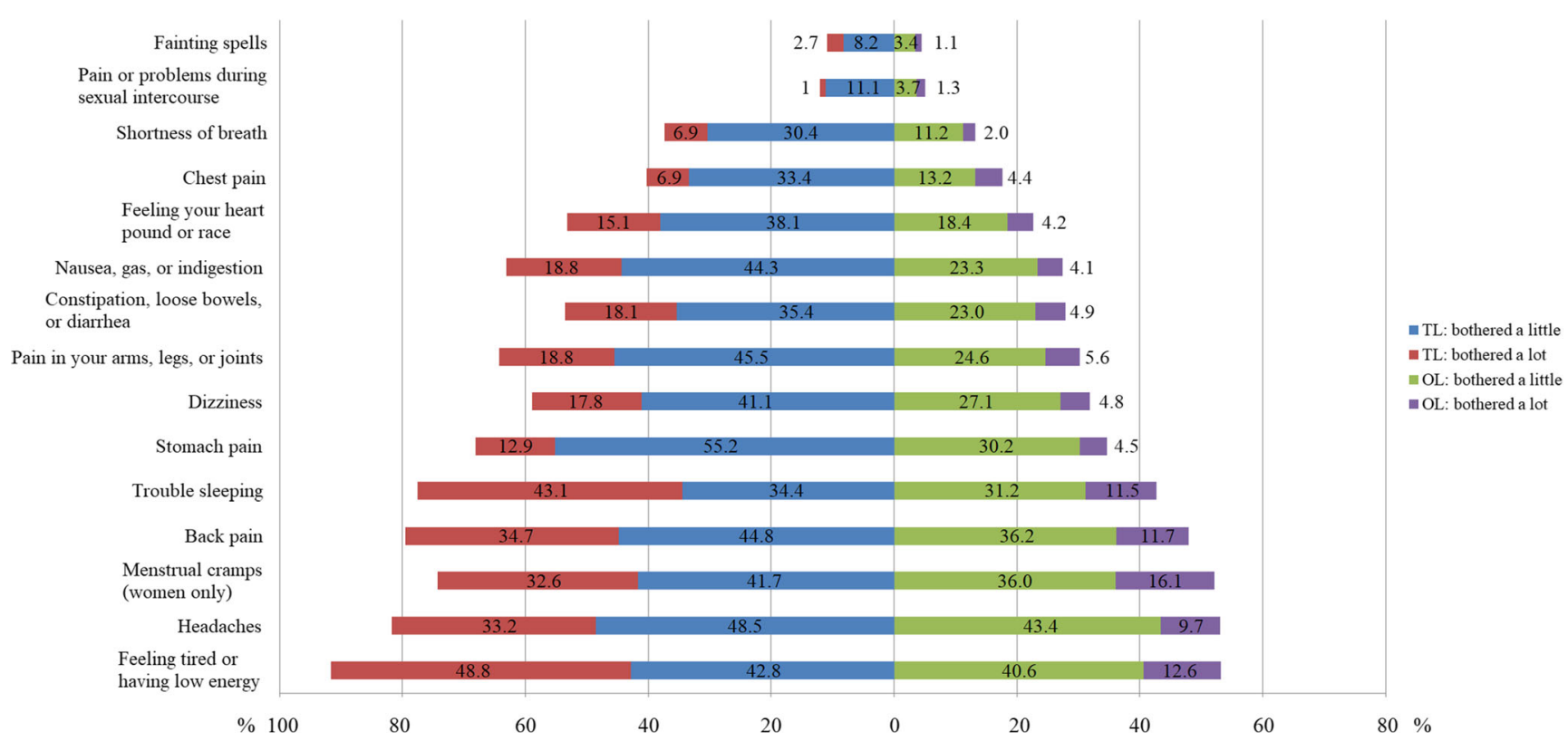

Fig. 2 Prevalence of somatic symptoms among medical students during TL $(N=619)$ and OL $(N=798)$

among students enrolled in OL. Statistically significant differences were obtained for depression, anxiety, and dissatisfaction with academic performance; the results are presented in Table 3.

Regression analysis revealed that there was a significant increase in depression in students who lived alone during quarantine $(p<0.05)$. It was also revealed that $44.4 \%$ of students were afraid of COVID-19. Sleep disturbances $(p<$ $0.05)$, headaches, and back pain $(p<0.001)$ associated with fear of COVID-19.

\section{Discussion}

This study conducted during the academic year (2019-2020) on 1 st- to 5th-year medical students illustrated the presence of the possible factors that could affect the mental state of students: a change in the method of training (the transition from TL to OL) and changes in the time to obtaining results.

An assessment of burnout syndrome showed a significant difference in averages among students during TL and OL regardless of gender and years of study, with the exception for 1 st years. However, the prevalence of burnout was lower in all study groups during OL compared with the TL period. General average scores on the CBI-S scale showed a significant difference between students during the TL and OL (40 and 33 , respectively, $p<0.001$ ). The overall prevalence of burnout was lower among students during OL (17\%), in comparison with results obtained in the period of TL $(28 \%)(p<$ 0.001) (Table 1). In contrast, Panagiotis et al. did not find significant differences in the prevalence of burnout among medical students during the pre-COVID-19 and COVID-19 periods. The prevalence of burnout decreased in 4th-year students. However, the level of cynicism increased in all study groups (1-6 years) after switching to OL. The authors suggest that such an increase in doubt and the importance of learning is associated with a lack of clinical experience [30].

Subscales of CBI-S significantly lowered the value of PB (38 vs 52), SRB (40 vs 51), and TRB (26 vs 32 ) in the period of OL compared to TL $(p<0.001)$. The prevalence of PB (31\% vs $56 \%$ ), SRB (34\% vs 55\%), and TRB (18\% vs $24 \%$ ) decreased among students during the OL compared to TL $(p<0.05)$. This means that OL students experienced less symptoms of fatigue and physical and emotional exhaustion compared to TL students. However, an analysis of the burnout by dimensions and academic year did not reveal any difference in SRB and TRB among 1st-year students (Table 2). The absence of a significant difference in the level of SRB and TRB among first-year students can be explained by the fact that they continued to adapt to their studies, and unlike senior students, they did not get used to the established features of traditional education.

All 6 items of PB and 7 items of SRB subscale had significant difference between TL and OL students $(p<0.001)$. According to studies related to burnout, the most pronounced differences were found in the following three questions: "Do you feel worn out at the end of the working day?", "Are you exhausted in the morning at the thought of another day at work?", and "Do you feel like every working hour is tiring for you?" (ESM 2). All of these items demonstrate the 
Table 3 Burnout, depression, and anxiety vs a change in academic performance among 1-5-year students during OL

\begin{tabular}{|c|c|c|c|c|}
\hline \multirow[t]{2}{*}{ Indicators } & \multicolumn{3}{|c|}{$\begin{array}{l}\text { How has your academic performance changed since } \\
\text { you switched to online learning? }\end{array}$} & \multirow[t]{2}{*}{$p$ value } \\
\hline & For the better & For the worse & Not changed & \\
\hline \multirow{2}{*}{$\begin{array}{l}\text { Burnout syndrome } \\
n, \%\end{array}$} & & & & \multirow[t]{3}{*}{0.096} \\
\hline & $42,19.81 \%$ & $24,20.17 \%$ & $50,13.77 \%$ & \\
\hline OR $(95 \% \mathrm{CI})$ & $1.55(0.99-2.43)$ & $1.58(0.92-2.71)$ & 1 & \\
\hline \multirow{2}{*}{$\begin{array}{l}\text { Depression (PHQ-9 } \geq 10) \\
n, \%\end{array}$} & & & & \multirow[t]{3}{*}{0.009} \\
\hline & $63,28.51 \%$ & $51,39.53 \%$ & $96,25.20 \%$ & \\
\hline OR $(95 \% \mathrm{CI})$ & $1.18(0.82-1.72)$ & $1.94(1.27-2.96)$ & 1 & \\
\hline \multirow{2}{*}{$\begin{array}{l}\text { Anxiety }(\mathrm{GAD}-7 \geq 10) \\
\quad n, \%\end{array}$} & & & & \multirow[t]{3}{*}{0.001} \\
\hline & $39,17.65 \%$ & $32,24.81 \%$ & $43,11.29 \%$ & \\
\hline OR $(95 \% \mathrm{CI})$ & $1.68(1.05-2.69)$ & $2.59(1.56-4.32)$ & 1 & \\
\hline \multirow{2}{*}{$\begin{array}{l}\text { Dissatisfaction with academic performance } \\
n, \%\end{array}$} & & & & \multirow[t]{2}{*}{$<0.001$} \\
\hline & $52,23.42 \%$ & $59,45.75 \%$ & $97,25.33 \%$ & \\
\hline OR $(95 \% \mathrm{CI})$ & $0.90(0.61-1.33)$ & $2.49(1.64-3.77)$ & 1 & \\
\hline
\end{tabular}

$n$, number; $O R$, odds ratio relationship between exhaustion and study routines. This allows us to assume that the decline in SRB after transition to $\mathrm{OL}$ is due to a change in the study schedule.

There were significant differences when comparing TRB rates among OL and TL students; however, item 20 (TRB-1) of CBI-S ("Do you find it hard to work with teachers?") stood out in particular. With the transition to OL, it had become easier for students to work with professors (ESM 2). In contrast, Abbasi et al. demonstrated that $84 \%$ of students indicated that the isolation of teacher-student interaction increased [31].

Only one item in the CRB subscale showed significant differences in average values ("Does it drain your energy to work with colleagues?"). This indicates that OL students spend more energy on working with colleagues compared to TL students (ESM 2). A study carried out among Indonesian medical students resulted in $63 \%$ of students indicating a lack of interaction [32]. Moreover, Meo et al. concluded that students showed a sense of emotional detachment from friends and fellow students during the COVID-19 quarantine [33]. The prevalence of CRB (13\% vs 17\%) had increased after the transition from TL to OL. This suggested that students during the $\mathrm{OL}$ are more prone to fatigue and emotional exhaustion as a result of changes in interpersonal relationships between colleagues, and the relationship between the last two was determined in a study by Rodríguez-Mantilla and Fernández-Díaz [34]. Students who had positive interactions with colleagues are more motivated [35], and show greater engagement, as well as demonstrate higher academic performance [36]. Knebel concluded that students have a great desire to socialize with their peers [37]. However, OL and introduced quarantine measures due to COVID-19 reduce the interaction between students, which in our opinion affected the colleague-related burnout. In the case of a recurrence of a similar pandemic where quarantine measures and online training are necessary, we recommend developing and implementing preventive actions to maintain positive interactions between students.

In a prospective cohort study performed in Malaysia, Yusoff et al. found that depression and anxiety significantly increased in students by the end of the academic year [38]. In turn, Aragon, Johnson, and Shaik did not find significant differences in the level of anxiety during TL and OL [39]. According to the results of this study, the prevalence of depression (49\% vs $28 \%$ ) and anxiety ( $42 \%$ vs $15.5 \%$ ) is significantly higher among students during the period of TL, compared with the period of OL $(p<0.001)$. Moreover, this study also showed that students who lived alone during the OL period were more prone to depression $(p<0.001)$. A study of 1090 healthcare workers in China found that participants who lived alone were about twice more likely to be depressed during the COVID-19 pandemic [40]. Another study conducted in the USA, but not during the pandemic, also found that living alone was associated with increased levels of depressive symptomatology [41].

A study conducted among college students in China during the COVID-19 epidemic revealed a prevalence of depression in $21 \%$ and anxiety in $27 \%$. The above study also concluded that non-medical students are more likely to be anxious [42], which may explain the lower rate obtained in our study. And the higher rates of depression in this study can be explained by a later collection of data, since excessive negative information about the COVID-19 is associated with a higher risk of depression.

We found that the presence of severe somatic symptoms was decreased more than 3 times (from 64 to 19\%) after the transition to OL. During OL (COVID-19 pandemic), most often students complained about the following symptoms: 
fatigue, headaches, menstrual pain, or other problems with the menstrual cycle in women, backache, and trouble sleeping (in more than $43 \%$ of cases). In one cross-sectional study that was conducted in China among college students, it was found that the frequency of somatic symptoms is $35 \%$. Moreover, concerns about COVID-19 had a positive correlation with the occurrence of somatic symptoms [43]. Cellini et al. found that sleep quality deteriorated after the introduction of restrictive measures due to the COVID-19 pandemic; sleep disturbance was associated with symptoms of anxiety, depression and stress [44]. In the current study, we found that sleep disturbances are associated with depression, anxiety $(p<0.001)$, and fear of COVID-19 $(p<0.05)$.

The decrease in burnout, depression, and anxiety during the period of OL can be explained by the following: elimination of spatial and temporal barriers, the motivation of self-education, and the decrease of costs of indirect expenses (transport, additional meals, and extra accommodation). Other factors that decreased burnout, depression, and anxiety are the ability to combine studying with personal and family life [45] and lack of interaction with patients during clinical placements. This also applied to students who lived with relatives during the OL period and therefore had more favorable conditions. In agreement with this, Cao et al. found that living with parents was a predictive factor against anxiety during COVID-19 [46]. A survey conducted by the dean's Head of AMU during the period of OL revealed that students responded positively to the following aspects of OL: availability of access to educational information at all times and from any location (65.3\%), learning independence increased $(47.1 \%)$, as well as more beneficial new educational technologies (42\%). Daroedono et al. indicated the following supporting factors: time and location flexibility, absence of specific preparation, and low cost (except for cellular data) [32]. However, the survey conducted by the Dean's office also pointed to certain problems in the organization of OL. Most often, students indicated the following difficulties in OL: poor Internet connection (51\%), lack of a personal computer (31\%), lack of a webcam (13\%); and 33\% of students indicated that they did not encounter any difficulties during the OL period. Pointing out the main problems of organizing online learning, students indicated the following: insufficient control of their knowledge and skills (47\%), unclear discipline requirements $(17 \%)$, insufficient feedback from teachers $(6 \%)$. These indicators will make it possible to organize OL more effectively in the future. A survey conducted at a later date (April 2020) indicated that satisfaction with the quality of OL had increased from 49 to $66 \%$.

The transition to OL occurred suddenly. The professors and students were not warned in advance. In the early days of OL, students and professors adapted to the new learning environment. Since students are more proficient in new technologies than professors, the learning environment was largely defined by students. During TL, the academic process was determined by the professors, which did not always coincide with the opinion of the students and thus made the learning environment more stressful. During online training, students became more independent and chose the time and conditions of learning, which could have a positive impact on mental health.

The current study finds satisfaction with academic performance was significantly higher among students during OL $(p<$ 0.001 ). This is also confirmed by the fact that, according to the results of the analysis by the Dean's office in the winter (20182019, period of TL) and summer (2019-2020 academic year of OL) after switching to OL, the percentage of students with the marks "Excellent" and "Good" increased from 76.5 to $85.5 \%$. However, a decrease in academic performance caused by transitioning to $\mathrm{OL}$ is associated with 2.5 times drop in satisfaction with academic performance. Strong relationship between satisfaction of students and academic performance was found by Dhaqane and Afrah [47]. Gonzalez et al. concluded that COVID-19 confinement changed students' learning strategies to a more continuous habit, improving their efficiency; a significant positive effect of the COVID-19 pandemic on students' performance resulted [48]. Allen et al. demonstrated in a meta-analysis study that online learning does not reduce student satisfaction compared to traditional teaching methods [49]. Olivet et al. determined that satisfaction was higher among students in the traditional form of study [50]. Al-Balas et al. resulted that only $27 \%$ of Jordanian students are satisfied with medical distance learning [51]. A study conducted among Jordanian university students concluded that using digital learning tools was the reason for low academic performance in $81.5 \%$ [18]. These results provide an opportunity to further research the relationship between adaptation to a new learning environment like OL and academic performance.

The most pronounced symptoms of depression and anxiety were prevalent in students who indicated that their academic performance had worsened during the OL $(p<0.05)$. Son et al. based on an interview survey study identified increased concerns in academic performance as stressor contributing to increased levels of stress, anxiety, and depressive thoughts among students due to the COVID-19 pandemic situation [52]. Over $40 \%$ of students noted fear of COVID-19, but this variable was not correlated to the mental state of the respondents. However, Bakioğlu, Korkmaz, and Ercan found a positive relationship between fear of COVID-19 and depression and anxiety [53].

\section{Conclusion}

This study conducted among Kazakhstan medical students revealed significant changes in students' mental state regarding burnout, depression, and anxiety, after switching to OL as a consequence of COVID-19 quarantine. Thus, it was found that burnout and the prevalence of depression, anxiety, and somatic symptoms among students were lower during the OL 
period compared with the same indicators during the TL period. Satisfaction with academic performance was higher in the period of OL, compared with TL period. However, negative changes in academic performance due to the OL have been associated with symptoms of depression and anxiety, and dissatisfaction with academic performance. The study provides evidence that OL not only helped in the fight against the spread of the virus during the pandemic but also had a positive impact on the mental state of students.

Supplementary Information The online version contains supplementary material available at https://doi.org/10.1007/s40670-020-01165-y.

Acknowledgments The authors thank the dean's office of the Faculty of Medicine at Astana Medical University for their support in this study.

Authors' Contributions Conceptualization: Aidos K. Bolatov and Altynay Zh. Askarova; methodology: Telman Z. Seisembekov and Altynay Zh. Askarova; formal analysis: Dariga S. Smailova; investigation: Raushan K. Baikanova; writing — original draft preparation: Aidos K. Bolatov; writing - review and editing: Elisa Fabbro; supervision: Telman Z. Seisembekov.

Data Availability All data available by request to corresponding author.

\section{Compliance with Ethical Standards}

Conflict of Interest The authors declare that they have no conflict of interest.

Ethics Approval The study was approved by the Local Ethics Committee of Astana Medical University (extract from protocol No. 3 of September 20, 2018).

Consent to Participate Not applicable.

Consent for Publication Not applicable.

Code Availability Not applicable.

\section{References}

1. Rose S. Medical student education in the time of COVID-19. JAMA. Published online March 31. 2020:2131-2. https://doi.org/ 10.1001/jama.2020.5227.

2. Sandhu P, de Wolf M. The impact of COVID-19 on the undergraduate medical curriculum. Med Educ Online. 2020;25(1):1764740. https://doi.org/10.1080/10872981.2020.1764740.

3. Mahase E. Covid-19: mental health consequences of pandemic need urgent research, paper advises. BMJ (Clinical research ed). 2020;369:m1515. https://doi.org/10.1136/bmj.m1515.

4. Vahedian-Azimi A, Moayed MS, Rahimibashar F, Shojaei S, Ashtari S, Pourhoseingholi MA. Comparison of the severity of psychological distress among four groups of an Iranian population regarding COVID-19 pandemic. BMC Psychiatry. 2020;20(1):402. https://doi.org/10.1186/s12888-020-02804-9.

5. Vindegaard N, Benros ME. COVID-19 pandemic and mental health consequences: systematic review of the current evidence.
Brain Behav Immun. 2020;S0889-1591(20)30954-5. Advance online publication. https://doi.org/10.1016/j.bbi.2020.05.048.

6. Shevlin M, Nolan E, Owczarek M, McBride O, Murphy J, Gibson Miller J, et al. COVID-19-related anxiety predicts somatic symptoms in the UK population. Br J Health Psychol. 2020;25:875-82. https://doi.org/10.1111/bjhp.12430 Advance online publication.

7. Majumdar P, Biswas A, Sahu S. COVID-19 pandemic and lockdown: cause of sleep disruption, depression, somatic pain, and increased screen exposure of office workers and students of India. Chronobiol Int. 2020:1-10. Advance online publication. https://doi. org/10.1080/07420528.2020.1786107.

8. Howlett D, Vincent T, Gainsborough N, Fairclough J, Taylor N, Cohen J, et al. Integration of a case-based online module into an undergraduate curriculum: what is involved and is it effective? ELearning Digit Media. 2009;6(4):372-84. https://doi.org/10.2304/ elea.2009.6.4.372.

9. Rajab MH, Gazal AM, Alkattan K. Challenges to online medical education during the COVID-19 pandemic. Cureus. 2020;12(7): e8966. https://doi.org/10.7759/cureus.8966.

10. Unpublished data: Hyseni Duraku, Zamira \& Hoxha, Linda. (2020). The impact of COVID-19 on higher education: a study of interaction among students' mental health, attitudes toward online learning, study skills, and changes in students' life. https://www. researchgate.net/publication/341599684_The_impact_of_COVID19_on_higher_education_A_study_of_interaction_among students $\% 27$ mental health_attitudes toward_online learning study_ski11s_and_changes_in_students $\overline{2} 27$ life. Accessed May 2020.

11. Patricia A. College students' use and acceptance of emergency online learning due to COVID-19. Int J Educ Res Open. 2020:100011. https://doi.org/10.1016/j.ijedro.2020.100011.

12. Aristovnik A, Keržič D, Ravšelj D, Tomaževič N, Umek L. Impacts of the COVID-19 pandemic on life of higher education students: a global perspective. Sustainability. 2020;12:8438. https://doi.org/10. 3390/su12208438.

13. Schaeffer CE, Konetes GD. Impact of learner engagement on attrition rates and student success in online learning. Int J Instr Technol Dist Learn. 2010;7(5):3-9.

14. Kahl TN, Cropley AJ. Face-to-face versus distance learning: psychological consequences and practical implications. Dist Educ. 1986;7(1):38-48. https://doi.org/10.1080/0158791860070104.

15. Hortulanus R, Machielse A, Meeuwesen L. Social isolation in modern society. London: Routledge; 2006. https://doi.org/10.4324/ 9780203020142.

16. Lazarevic B, Bentz D. Student perception of stress in online and faceto-face learning: the exploration of stress determinants. Am J Dist Educ. 2020:1-14. https://doi.org/10.1080/08923647.2020.1748491.

17. Hendrix E. Assessing student stress in clinical laboratory science programs: online versus face-to-face. Clin Lab Sci. 2016;29(2):99 $100 \mathrm{http} / /$ hdl.handle.net/2346/60109. Accessed December 2014.

18. Haider AS, Al-Salman S. Dataset of Jordanian University students' psychological health impacted by using e-learning tools during COVID-19. Data Brief. 2020:106104. https://doi.org/10.1016/j. dib.2020.106104.

19. Gossenheimer AN, Bem T, Carneiro ML, de Castro MS. Impact of distance education on academic performance in a pharmaceutical care course. PLoS One. 2017;12(4):e0175117. https://doi.org/10. 1371/journal.pone.0175117.

20. Pei L, Wu H. Does online learning work better than offline learning in undergraduate medical education? A systematic review and meta-analysis. Med Educ Online. 2019;24(1):1666538. https://doi.org/ 10.1080/10872981.2019.1666538.

21. Hasan N, Bao Y. Impact of "e-Learning crack-up" perception on psychological distress among college students during COVID-19 pandemic: a mediating role of "fear of academic year loss". Child 
Youth Serv Rev. 2020;118:105355. https://doi.org/10.1016/j. childyouth.2020.105355.

22. Kristensen TS, Borritz M, Villadsen E, Christensen KB. The Copenhagen Burnout Inventory: a new tool for the assessment of burnout. Work Stress. 2005;19:192-207. https://doi.org/10.1080/ 02678370500297720 .

23. Campos JADB, Carlotto MS, Marôco J. Copenhagen Burnout Inventory - student version: adaptation and transcultural validation for Portugal and Brazil. Psicologia. 2013;26(1):87-97. https://doi. org/10.1590/S0102-79722013000100010.

24. Borritz M, Rugulies R, Bjorner JB, Villadsen E, Mikkelsen OA, Kristensen TS. Burnout among employees in human service work: design and baseline findings of the PUMA study. Scand J Public Health. 2006;34(1):49-58. https://doi.org/10.1080/ 14034940510032275 .

25. Kroenke K, Spitzer RL. The PHQ-9: a new depression diagnostic and severity measure. Psychiatr Ann. 2002;32(9):509-15. https:// doi.org/10.3928/0048-5713-20020901-06.

26. Kroenke K, Spitzer RL, Williams JB, Löwe B. The Patient Health Questionnaire Somatic, Anxiety, and Depressive Symptom Scales: a systematic review. Gen Hosp Psychiatry. 2010;32(4):345-59. https://doi.org/10.1016/j.genhosppsych.2010.03.006.

27. Spitzer RL, Kroenke K, Williams JB, Löwe B. A brief measure for assessing generalized anxiety disorder: the GAD-7. Arch Intern Med. 2006;166(10):1092-7. https://doi.org/10.1001/archinte.166.10.1092.

28. Kroenke Kurt, Spitzer Robert L, and Williams Janet BW. DSW The PHQ-15: Validity of a new measure for evaluating the severity of somatic symptoms. Psychosom Med: March-April 2002 - Volume 64 - Issue 2 - p 258-266.

29. Snell WJ, Finney P. In: Davis C, Yarber W, Bauserman R, editors. Multidimensional AIDS anxiety questionnaire, in handbook of sexuality-related measures. Thousand Oaks: Sage Publications; 1998. p. 351-3.

30. Panagiotis Zis, Artemios Artemiadis, Panagiotis Bargiotas et al. Medical studies during the COVID-19 pandemic: the impact of digital learning on burnout and mental health, 21 August 2020, PREPRINT (Version 1) available at Research Square [+10.21203/ rs.3.rs-63097/v1+]

31. Abbasi S, Ayoob T, Malik A, Memon SI. Perceptions of students regarding E-learning during Covid-19 at a private medical college. Pakistan J Med Sci. 2020;36(COVID19-S4):S57-61. https://doi. org/10.12669/pjms.36.COVID19-S4.2766.

32. Daroedono E, Siagian F, Alfarabi M, Cing J, Arodes E, Sirait R, et al. The impact of COVID-19 on medical education: our students perception on the practice of long distance learning. Int $\mathrm{J}$ Community Med Public Health. 2020;7(7):2790-6. https://doi. org/10.18203/2394-6040.ijcmph20202545.

33. Meo SA, Abukhalaf AA, Alomar AA, Sattar K, Klonoff DC. COVID-19 pandemic: impact of quarantine on medical students' mental wellbeing and learning behaviors. Pakistan J Med Sci. 2020;36(COVID19-S4):S43-8. https://doi.org/10.12669/pjms.36. COVID19-S4.2809.

34. Rodríguez-Mantilla JM, Fernández-Díaz MJ. The effect of interpersonal relationships on burnout syndrome in Secondary Education teachers. Psicothema. 2017;29(3):370-7. https://doi.org/10.7334/ psicothema2016.309.

35. Furrer C, Skinner E. Sense of relatedness as a factor in children's academic engagement and performance. J Educ Psychol. 2003;95(1):148-62. https://doi.org/10.1037/0022-0663.95.1.148.

36. Liem GA, Martin AJ. Peer relationships and adolescents' academic and non-academic outcomes: same-sex and opposite-sex peer effects and the mediating role of school engagement. British J Educ Psychol. 2011;81(Pt 2):183-206. https://doi.org/10.1111/j.20448279.2010.02013.x.

37. Knebel E (2001). The use and effect of distance education in healthcare: What do we know? Operations Research Issue Paper
2(2). Bethesda, MD: Published for the U.S. Agency for International Development (USAID) by the Quality Assurance Project.

38. Yusoff MSB, Mat Pa MN, Esa AR, Abdul Rahim AF. Mental health of medical students before and during medical education: a prospective study. J Taibah Univ Med Sci. 2013;8(2):86e92.

39. Aragon SR, Johnson SD, Shaik N. The influence of learning style preferences on student success in online versus face-to-face environments. Am J Dist Educ. 2000;16:227-43.

40. Liu Y, Chen H, Zhang N, Wang X, Fan Q, Zhang Y, et al. Anxiety and depression symptoms of medical staff under COVID-19 epidemic in China. J Affect Disord. 2020;278:144-8. Advance online publication. https://doi.org/10.1016/j.jad.2020.09.004.

41. Stahl ST, Beach SR, Musa D, Schulz R. Living alone and depression: the modifying role of the perceived neighborhood environment. Aging Ment Health. 2017;21(10):1065-71. https://doi.org/ 10.1080/13607863.2016.1191060.

42. Chang J, Yuan Y, Wang D. Nan fang yi ke da xue xue bao = Journal of Southern Medical University. 2020;40(2):171-6. https://doi.org/ 10.12122/j.issn.1673-4254.2020.02.06.

43. Liu S, Liu Y, Liu Y. Somatic symptoms and concern regarding COVID-19 among Chinese college and primary school students: a cross-sectional survey. Psychiatry Res. 2020;289:113070. Advance online publication. https://doi.org/10.1016/j.psychres.2020.113070.

44. Cellini N, Canale N, Mioni G, Costa S. Changes in sleep pattern, sense of time and digital media use during COVID-19 lockdown in Italy. J Sleep Res. 2020:e13074. Advance online publication. https://doi.org/10.1111/jsr.13074.

45. Rurato P. Learner Characteristics in Distance Education (DE): Presentation of an instrument and context, in Cibertextualidades, 4 (edição bilingue), Edições UFP, 2011, pp.73-88.

46. Cao W, Fang Z, Hou G, Han M, Xu X, Dong J, et al. The psychological impact of the COVID-19 epidemic on college students in China. Psychiatry Res. 2020;287:112934. https://doi.org/10.1016/j. psychres.2020.112934.

47. Dhaqane MK, Afrah NA. Satisfaction of students and academic performance in Benadir University. J Educ Pract. 2016;7:59-63.

48. Gonzalez T, Rubia M, Hincz KP, Comas-Lopez M, Subirats L, Fort $S, \&$ Sacha G (2020). Influence of COVID-19 confinement in students performance in higher education. ArXiv, https://arxiv.org/ abs/2004.09545.

49. Allen M, Bourhis J, Burrell N, Mabry E. Comparing student satisfaction with distance education to traditional classrooms in higher education: a meta-analysis. Am J Dist Educ. 2002;16(2):83-97. https://doi.org/10.1207/S15389286AJDE1602_3.

50. Olivet J, Zerger S, Greene RN, Kenney RR, Herman DB. Online versus face-to-face training of critical time intervention: a matching cluster randomized trial. Am J Dist Educ. 2016;30:237-49. https:// doi.org/10.1080/08923647.2016.1232107.

51. Al-Balas M, Al-Balas HI, Jaber HM, Obeidat K, Al-Balas H, Aborajooh EA, et al. Distance learning in clinical medical education amid COVID-19 pandemic in Jordan: current situation, challenges, and perspectives. BMC Med Educ. 2020;20(1):341. https:// doi.org/10.1186/s12909-020-02257-4.

52. Son C, Hegde S, Smith A, Wang X, Sasangohar F. Effects of COVID-19 on college students' mental health in the United States: interview survey study. J Med Internet Res. 2020;22(9): e21279. https://doi.org/10.2196/21279.

53. Bakioğlu F, Korkmaz O, Ercan H. Fear of COVID-19 and positivity: mediating role of intolerance of uncertainty, depression, anxiety, and stress. Int J Ment Heal Addict. 2020. https://doi.org/10. 1007/s11469-020-00331-y.

Publisher's Note Springer Nature remains neutral with regard to jurisdictional claims in published maps and institutional affiliations. 